\title{
Correction to: Titanium lons Inhibit the Bacteria in Vase Solutions of Freshly Cut Gerbera jamesonii and Extend the Flower Longevity
}

\author{
Cai-Xia $\mathrm{Li}^{1} \cdot$ Yan-Fen Fan ${ }^{1,2} \cdot$ Wei Luan ${ }^{1,2} \cdot$ Ya Dai $^{1,2} \cdot$ Ming-Xiu Wang $^{1,2} \cdot$ Chun-Mei Wei ${ }^{1,2} \cdot$ Yan Wang ${ }^{1} \cdot$ Xiang Tao $^{1}$. \\ Ping Mao ${ }^{1} \cdot$ Xin-Rong Ma ${ }^{1}$
}

Published online: 17 August 2020

(C) Springer Science+Business Media, LLC, part of Springer Nature 2020

\section{Correction to: Microbial Ecology \\ https://doi.org/10.1007/s00248-018-1273-2}

We request that the following corrections be made in our article:

"This work was supported by the National Key Research and Development Program of China (Grant No. 2017YFD0201301) and the Key Research and Development Program of Sichuan (Grant No. 2018NA0027)" must be changed with:

This work was supported by the National Key Research and Development Program of China (Grant No. 2017YFD0201301) and the Key Research and Development Program of Sichuan (Grant No. 2018NZ0027).

The online version of the original article can be found at https://oi.org/ 10.1007/s00248-018-1273-2

Xin-Rong Ma

maxr@cib.ac.cn

1 Chengdu Institute of Biology, Chinese Academy of Sciences, No. 9, Section 4, Renmin South Road, Chengdu 610041, Sichuan, People's Republic of China

2 University of Chinese Academy of Sciences, Beijing, China 